\title{
The Effect of Cocoa Beans Heavy and Trace Elements on Safety and Stability of Confectionery Products
}

\author{
*Vineta Vìtola, Inga Ciproviča \\ Latvia University of Agriculture, Rigas street 22, Jelgava, LV-3004, Latvia
}

\begin{abstract}
The aim of the study was to evaluate cocoa beans quality produced in Cameroon, Ecuador, Nigeria and Ghana from safety position determining heavy and trace metals concentration and evaluating the oxidative stability of confectionery products prototypes (trials) with analysing cocoa beans. For evaluation of oxidative stability of confectionery products, the main ingredients - butter and cocoa beans kernels were tested making trials as milk chocolate prototype.

The composition of confectionery ingredients affects quality of products; therefore it is very important to evaluate quality of raw materials in confectionery industry, as they are purchased practically in all regions of the world.

Mercury, arsenic, lead, cadmium concentration was determined in whole cocoa beans as their presence in foods have toxic effect on human beings and their concentration are strictly limited as maximum residue limits for processing. Cocoa shells can be used as additive to confectionery products recipes therefore the object of the study was cocoa beans and cocoa shells.

Analyzing cocoa beans quality indices there was established that lead, cadmium, aluminium and zinc concentrations vary in cocoa beans significantly. Differences in lead concentration in cocoa beans from Ghana, Cameroon and Ecuador were significant $(\mathrm{p}<0.05)$ compared with concentration of lead in cocoa beans from Nigeria $(\mathrm{p}>$ 0.05). Cadmium concentration in cocoa beans from Cameroon was significantly different comparing with cocoa beans from Nigeria, Ecuador and Ghana $(p>0.05)$. Differences in aluminium concentration in cocoa beans kernels were significant $(\mathrm{p}<0.05)$ in all analyzed samples. Concentration of zinc was higher in shells of cocoa beans, especially in shells of cocoa beans from Ecuador $(\mathrm{p}<0.05)$. The presence of cocoa products in milk chocolate prototypes inhibited the speed of lipid peroxidation. The different trace and heavy metals concentrations in cocoa beans should be taken into account choosing ingredients and components for confectionary products production particularly those with high content of cocoa (chocolates, sweets, cocoa fillings, cocoa creams and others) with the aim to prevent oxidation process during shelf-life of products.
\end{abstract}

Key words: cocoa beans, heavy, trace metals, peroxides.

\section{Introduction}

Cocoa products are widely consumed foods worldwide. Cocoa beans are raw materials for production of chocolate, candies, cocoa powder and beverages. Heavy and trace metals presence in these products is a result of their accumulation in the cocoa beans during vegetation. The concentration of cadmium, lead, copper and arsenic in cocoa beans is of the interest as these metals or trace elements (in high concentrations) are generally considered as toxic to human beings. A lot of researchers have investigated the content of cadmium $(\mathrm{Cd})$, copper $(\mathrm{Cu})$, lead $(\mathrm{Pb})$, and arsenic (As) in cocoa beans from various countries as well as in some chocolate products. Heavy metals such as $\mathrm{Pb}, \mathrm{Cd}$, and trace element $-\mathrm{Cu}$ are generally regarded as environmental contaminants and their presence in foods have toxic effect in human.

Due to the importance of heavy metals on human health, the European Commission has set up maximum residue limits for specific heavy metals in cocoa beans in Regulations setting maximum levels for certain contaminants in foodstuffs (Setting maximum levels for certain contaminants in foodstuffs, 2006; Maximum levels of cadmium in foodstuffs, 2014). Therefore, it is very important to evaluate the quality of raw materials in confectionery industry, as they are purchased practically in all regions of the world.

Ingredients that are used in production of confectionery products and desirable constituents which are formed during production processes and shelf-life affect

\footnotetext{
* Corresponding Author's email: 
nutritional value of products (Fennema, 1985). One of the factors that can reduce the quality of products and can have a negative effect on human health is fat oxidation products in the form of peroxides in food.

Peroxides/hydroxiperoxides and free radicals can be undesirable compounds in food products (Erickson, 2002; Pokorny, 2006). Peroxides are formed from lipids in the presence of oxygen. This process can be promoted by the presence of metal ions as well as heavy and trace elements that contain ingredients in cocoa beans. For prevention of oxidation process antioxidants are added in confectionery products production. Beside food additives, a lot of confectionary ingredients have antioxidant properties due to high concentration of phenolic compounds or fat soluble vitamins.

The aim of the study was to evaluate cocoa beans quality produced in Cameroon, Ecuador, Nigeria and Ghana from safety position determining heavy and trace metals concentration and evaluating the oxidative stability of confectionary products prototypes (trials) with analysing cocoa beans.

\section{Materials and Methods}

The object of the study was Forastero type of cocoa beans from different producers. Heavy metals and trace elements concentration was analysed in cocoa beans purchased from Cameroon, Ecuador, Nigeria and Ghana. ISO 2451:2014 standard specifies the requirements for sampling of cocoa beans. Cocoa beans were selected from 10 bags of $60 \mathrm{~kg}$ net per bag with a shelf life of around four months. Cocoa beans samples were taken from middle, top and bottom of each bag. It was $10 \%$ of the batch. Cocoa beans were mixed and $200 \mathrm{~g}$ of cocoa beans were selected and weighted for analyses.

Selenium, zinc and aluminium content was determined in cocoa beans kernels and shells. Analyses of heavy and trace metals were made in Food Safety and Animal Health and Environmental Research Institute "Bior".

Mercury, arsenic, lead and cadmium concentrations were determined according to standard procedures. Mercury was analysed according to ISO 6637-1984 (E) standard procedure, arsenic, lead and cadmium ac- cording to AOAC 986.15. (1995) method.

Trace elements (selenium, zinc and aluminium) were determined in cocoa beans kernels and shells according to AOAC 986.15. (1995) method.

Forecasting different heavy metals and trace elements concentrations in cocoa beans and their influence on confectionary products quality, oxidative stability of main confectionary ingredients was tested making trials with butter and $36 \%$ of roasted and ground cocoa beans kernels. Cocoa concentration in experimental samples was similar to cocoa concentration in classical milk chocolate. Sweet cream butter (producer - SC Riga dairy) with the fat content of $82.5 \%$ and moisture content of $16 \%$ was used for the experiments. Peroxide value of butter prior investigation was $0.26 \mathrm{mmol} \mathrm{kg}^{-1}$.

Peroxide value was determined according to Wheeler's method (Matiseks, Snepels, \& Steinere, 1998). Peroxide value was tested in butter with $36 \%$ roasted and ground cocoa beans kernels after 30 days of incubation at $28 \pm 2^{\circ} \mathrm{C}$. All samples were prepared in the same conditions and mixed for one minute. Mixed samples were put into Petri plates and kept in an incubator. After that the quantity of peroxides was determined. Chosen parameters correspond to accelerated food shelf-life testing in confectionery industry.

Statistical data analysis was used analyzing differences between cocoa beans and their oxidative stability during accelerated food shelf-life testing. Data were analyzed by one factor dispersion analysis using MS Excel and SPSS program package SPSS 11.0. All tests were regarded as statistically significant when $\mathrm{p}<0.05$.

\section{Results and Discussion}

The concentration of heavy metals determined in different origin cocoa beans showed in Table 1.

The results revealed that heavy metal concentration especially lead and cadmium significantly varied in the cocoa beans from different countries. No differences were observed among the countries for mercury and arsenic concentrations in cocoa beans. The highest total concentration of $\mathrm{Cd}$ was found in cocoa beans from Ecuador.

Table 1

The concentration of heavy metals in cocoa beans

\begin{tabular}{|c|c|c|c|c|c|}
\hline \multirow[t]{2}{*}{ Indicators } & \multirow{2}{*}{$\begin{array}{l}\text { Limit } \\
\mathrm{mg} \mathrm{kg}^{-1}\end{array}$} & \multicolumn{4}{|c|}{ Cocoa beans origin } \\
\hline & & Cameroon, $\mathrm{mg} \mathrm{kg}^{-1}$ & Ecuador, $\mathrm{mg} \mathrm{kg}^{-1}$ & Nigeria, $\mathrm{mg} \mathrm{kg}^{-1}$ & Ghana, $\mathrm{mg} \mathrm{kg}^{-1}$ \\
\hline Mercury $^{*}$ & 0.1 & $<0.01$ & $<0.01$ & $<0.01$ & $<0.01$ \\
\hline Arsenic* & 1.0 & $<0.06$ & $<0.06$ & $<0.06$ & $<0.06$ \\
\hline Lead & 1.0 & $0.37 \pm 0.05 b$ & $0.33 \pm 0.04 b$ & $0.52 \pm 0.07 \mathrm{a}$ & $0.32 \pm 0.04 b$ \\
\hline Cadmium & 0.5 & $0.05 \pm 0.01 b$ & $0.20 \pm 0.04 a$ & $0.020 \pm 0.003 c$ & $0.017 \pm 0.003 \mathrm{c}$ \\
\hline
\end{tabular}

${ }^{*}$ The method allows determination of value starting from $0.01 \mathrm{mg} \mathrm{kg}^{-1}$

The number of replicates $n=3 ; a, b, c-$ samples with a similar letter superscripts do not differ significantly $(p>0.05)$ 
The highest total concentration of $\mathrm{Cd}$ was found in cocoa beans from Ecuador. In the analysed samples cadmium residues range from $0.017-0.2 \mathrm{mg} \mathrm{kg}^{-1}$ (Table 1). Data on Cd residues in cocoa beans is scarce probably due to the fact that $\mathrm{Cd}$ contamination in agricultural soils is rare. Consequently, the European Union (Maximum levels of cadmium in foodstuffs, 2014) has set a maximal allowable residue limit of 0.5 $\mathrm{mg} \mathrm{kg}^{-1}$ for $\mathrm{Cd}$ in cocoa powder. However, the level of cadmium in cocoa beans analyzed in this work may not pose any significant health hazard due to relatively low concentration.

$\mathrm{Pb}$ residues in cocoa beans obtained from different countries varied from 0.32 to $0.52 \mathrm{mg} \mathrm{kg}^{-1}$. Cocoa beans obtained from Ghana and Ecuador had $\mathrm{Pb}$ residues significantly lower than beans obtained from Nigeria. All purchased cocoa beans had $\mathrm{Pb}$ residues under maximum permissible levels $\left(1.0 \mathrm{mg} \mathrm{kg}^{-1}\right)$ set by Commission Regulation No 1881/2006. Lead is a toxic chemical and may cause damages to kidneys, cardiovascular, immune, hematopoietic, central nervous and reproductive systems (European Food Safety Authority, 2006). A potentially important source of lead contamination in cocoa beans is tetra-ethyl lead additive in gasoline, which is still common in many African countries (Rankin et al., 2005). For example, Nigerian gasoline contains $0.4-0.8 \mathrm{~g} \mathrm{~L}^{-1}$ lead, which is among the highest in the world (Rankin et al., 2005). Overall, it might be difficult to name precisely the source of $\mathrm{Pb}$ in cocoa plantations but the fact remains that the level of $\mathrm{Pb}$ in cocoa beans is traceable to $\mathrm{Pb}$ content in the soil.

According to information mentioned in literature sources Ghana is the second largest cocoa bean producer in the world. Undeniably, cocoa from Ghana is revered to be of the highest quality with high demand in the world market. Due to these quality characteristics of Ghana's cocoa beans, they are mostly used as reference standard for cocoa beans produced from other parts of the world (Fold, 2008). The situation is becoming alarming due to the fact that a lot of cocoa farmers now apply insecticides, herbicides, fungicides and fertilizers on their cocoa farms to control pests and to enhance maximum bean yield. These activities are likely to increase heavy or trace metals like $\mathrm{Cd}, \mathrm{Fe}, \mathrm{Pb}, \mathrm{Cu}$, $\mathrm{Mn}$ and $\mathrm{Zn}$ into the soil which eventually will end up in the edible parts of the crops through phytoextraction by the crops and translocation throughout the plant system (Thomas, 2015).

\section{Selenium, zinc and aluminium concentration in cocoa beans}

\begin{tabular}{|c|c|c|c|c|c|c|}
\hline \multirow{2}{*}{$\begin{array}{l}\text { Place of cocoa } \\
\text { beans origin }\end{array}$} & \multicolumn{3}{|l|}{ Kernels } & \multicolumn{3}{|l|}{ Shells } \\
\hline & $\begin{array}{l}\mathrm{Se}^{*} \\
\mathrm{mg} \mathrm{kg}^{-1}\end{array}$ & $\begin{array}{l}\mathrm{Zn} \\
\mathrm{mg} \mathrm{kg}^{-1}\end{array}$ & $\begin{array}{l}\mathrm{Al} \\
\mathrm{mg} \mathrm{kg}^{-1}\end{array}$ & $\begin{array}{l}\mathrm{Se}^{*} \\
\mathrm{mg} \mathrm{kg}^{-1}\end{array}$ & $\begin{array}{l}\mathrm{Zn} \\
\mathrm{mg} \mathrm{kg}^{-1}\end{array}$ & $\begin{array}{l}\mathrm{Al} \\
\mathrm{mg} \mathrm{kg}^{-1}\end{array}$ \\
\hline Cameroon & $<0.1$ & $50 \pm 5 a$ & $9.2 \pm 0.9 \mathrm{~d}$ & $<0.1$ & $60 \pm 6 b$ & $4.6 \pm 0.5 \mathrm{c}$ \\
\hline Ecuador & $<0.1$ & $58 \pm 6 a$ & $12 \pm 1 c$ & $<0.1$ & $190 \pm 20 a$ & $9.1 \pm 0.9 b$ \\
\hline Nigeria & $<0.1$ & $49 \pm 5 a$ & $16 \pm 2 b$ & $<0.1$ & $61 \pm 6 b$ & $9.8 \pm 0.9 b$ \\
\hline Ghana & $<0.1$ & $51 \pm 5 a$ & $54 \pm 5 a$ & $<0.1$ & $68 \pm 7 b$ & $68 \pm 7 a$ \\
\hline
\end{tabular}

The method allows determination of value starting from $0.1 \mathrm{mg} \mathrm{kg}^{-1}$

The number of replicates $n=3 ; a, b, c-$ samples with a similar letter superscripts do not differ significantly $(p>0.05)$

Cocoa bean shells are equivalent to kernels by content of trace elements with some exceptions. Zinc concentration ranged from 49 to $58 \mathrm{mg} \mathrm{kg}^{-1}$ in kernels and from 61 to $190 \mathrm{mg} \mathrm{kg}^{-1}$ in shells. There was no significant difference $(\mathrm{p}>0.05)$ in $\mathrm{Zn}$ content among the analyzed kernels samples. Concentration of zinc was higher in shells of cocoa beans, especially in shells of cocoa beans from Ecuador and differences between samples are significant $(\mathrm{p}<0.05)$. The results showed (Table 2$)$ that the content of $\mathrm{Zn}$ exceeded recommended dietary allowance per day (average $14 \mathrm{mg}$ for adults and the upper limit is set at $40 \mathrm{mg} \mathrm{day}^{-1}$ for all foods, water and supplements) (Ministry of Health, 2008). The results have revealed that the average concentration of zinc in cocoa bean shells from Ecuador was the highest comparing with cocoa bean shells data from Nigeria, Ghana, and Cameroon. The most important information reported on zinc toxicity is its interference with copper metabolism. The symptoms that an acute oral Zn dose may provoke are tachycardia, vascular shock, dyspeptic nausea, vomiting, diarrhoea, pancreatitis and damage of hepatic parenchyma (European Food Safety Authority, 2006). Selenium was not detected in any samples of cocoa beans kernels and shells.

Great interest is focused on cocoa and cocoa products for their beneficial health effect because of the high levels of antioxidants they contain. The European Food Safety Authority (EFSA) has approved that fla- 
vonoids in cocoa and chocolate products are associated with a lower risk of cardiovascular disease (European Food Safety Authority, 2012).

The antioxidants potential of cocoa beans components was approved through accelerated food shelf-life testing results of experimental samples that are showed in Table 3. Authors decided to measure peroxide value of experimental samples only after 30 days of incubation and obtained results to compare with butter perox- ide value data. In this case we analysed different oxidation speed of samples with and without cocoa beans additives.

The experiment showed that there were not significant differences between samples with cocoa beans kernels from Ghana and Nigeria during storage time $(p>0.05)$ and their oxidative stability was practically the same.

\section{Peroxide value of analysed samples}

Table 3

\begin{tabular}{|l|c|c|}
\hline Samples & $\begin{array}{c}\text { Peroxides value, mmol kg-1 } \\
\text { before storage }\end{array}$ & $\begin{array}{c}\text { Peroxides after 30 days of storage, } \\
\mathrm{mmol} \mathrm{kg}^{-1}\end{array}$ \\
\hline Butter (control sample) & $0.26 \pm 0.02$ & $0.65 \pm 0.01 \mathrm{a}$ \\
\hline $\begin{array}{l}\text { Butter with roasted cocoa beans kernels } \\
\text { from Cameroon }\end{array}$ & & $0.35 \pm 0.02 \mathrm{c}$ \\
\cline { 1 - 1 } $\begin{array}{l}\text { Butter with roasted cocoa beans kernels } \\
\text { from Ecuador }\end{array}$ & - & $0.16 \pm 0.01 \mathrm{~d}$ \\
\cline { 1 - 1 } $\begin{array}{l}\text { Butter with roasted cocoa beans kernels } \\
\text { from Ghana }\end{array}$ & & $0.49 \pm 0.01 \mathrm{~b}$ \\
\cline { 1 - 3 } $\begin{array}{l}\text { Butter with roasted cocoa beans kernels } \\
\text { from Nigeria }\end{array}$ & & $0.51 \pm 0.02 \mathrm{~b}$ \\
\hline
\end{tabular}

The number of replicates $n=3 ; a, b, c, d-$ samples with a similar letter superscripts do not differ significantly $(p>0.05)$

It was established that cocoa shells have antioxidants effect (Bruna et al., 2010; Vitola \& Strautnieks, 2004; Vitola, Karklina, \& Strautnieks, 2005) but in this study we concluded that cocoa bean kernels could have antioxidant potential, too. The research established that the most effective peroxides formation was eliminated in the sample with Ecuador cocoa beans (Table 3). This statement we could explain by analysing zinc results (58 $\mathrm{mg} \mathrm{kg}^{-1}$ in kernels and $190 \mathrm{mg} \mathrm{kg}^{-1}$ in shells) because the ability of zinc to retard oxidative processes has been recognized for many years (Powel, 2000). The presence of cocoa products in samples inhibited lipid peroxidation but according to findings of Andujar and co-authors (Andujar et al., 2012) had no effect on the hydroxyl radical, nor did it exhibit ferrous chelating activity. Metal chelating capacity reduces the concentration of the catalyzing transition metal in lipid peroxidation (Schinella et al., 2010) and with this statement we can explain our study results. However, because the polyphenol-rich cocoa extract showed neither ferrous nor copper chelating activity, it most likely acts as a chain-breaking antioxidant (Andujar et al., 2012). Cocoa beans composition was heavy and trace elements could influence lipids stability fastening or delaying peroxides formation in confectionery products.

\section{Conclusions}

1. Lead, cadmium, aluminium and zinc concentrations significantly vary in analyzing cocoa beans. No differences were observed among the countries for mercury and arsenic concentrations.

2. The different trace and heavy metal concentrations in cocoa beans should be taken into account by choosing ingredients and components for confectionery products production with the aim to prevent oxidation process during shelf-life of products.

3. The research established that the higher zinc concentration in the sample with Ecuador cocoa beans kernels prevents peroxide formation comparing with Cameroon, Ghana and Nigeria cocoa beans kernels.

\section{References}

1. Andújar, I., Recio, M. C., Giner, R. M., \& Ríos, J. L. (2012). Cocoa Polyphenols and Their Potential Benefits for Human Health. Oxidative Medicine and Cellular Longevity, 2012 (906252), 1-23. DOI:10.1155/2012/906252.

2. Bruna, C., Eichholz, L., Rohn, S., Kroh, L.W., \& Huyskens-Keil, S. (2010). Bioactive compounds and antioxidant activity of cocoa hulls (Theobroma cocoa L.) from different origins. Journal of Applied Botany and Food Quality, 83(1), 9-13. 
3. European Food Safety Authority (2006). Tolerable upper intake levels for vitamins and minerals. Retrieved December 8, 2015, from http://www. efsa.europa.eu/sites/default/ files/efsa rep/blobserver_assets/ndatolerableuil.pdf.

4. European Food Safety Authority (2012). Scientific Opinion on the substantiation of a health claim related to cocoa flavonols and maintenance of normal endothelium-dependent vasodilatation pursuant to Article 13(5) of Regulation (EC) No 1924/2006. Retrieved December 8, 2015, from http://www.acticoa.com/uploads/EFSA_opinion.pdf.

5. Erickson, M.C. (2002). Chemistry and function of phospholipids. In C.C. Akoh \& D.B. Min (Eds.), Food lipids chemistry, nutrition, and biotechnology (pp. 39-55). New York: Marcel Dekker, Inc.

6. Setting maximum levels for certain contaminants in foodstuffs. (2006). European Commission Regulation (EC) No 1881/2006 of 19 December 2006. Brussels: Official Journal of European Union $\mathrm{L} 364 / 5$.

7. Maximum levels of cadmium in foodstuffs. (2014). European Commission Regulation No. 488 amending Regulation No.1881/2006. Brussels: Official Journal of the European Union L 138.

8. Fennema, O. (1985). Chemical changes in food during processing - an overview. In T.Richardson (Ed.), Chemical changes in food during processing (pp. 1-10). New York: Springer Science, Business Media LLC.

9. Fold, N. (2008). Transnational sourcing practices in Ghana's perennial crop sectors. Journal of Agrarian change, 8 (1), 94-122. DOI: 10.1111/j.1471-0366.2007.00164.x.

10. Matiseks, R., Snepels, F.M., \& Steinere, G.(1998). Analytical chemistry of food. Riga: University of Latvia (in Latvian).

11. Ministry of Health. (2008). The recommended dose of energy and nutrients of Latvian citizens. Latvia: Health Ministry's Decree No.174 from 15 October 2008.
12. Pokorny, J. (2006). Production, separation and modification of phospholipids for use in food. In F.D. Gustone (Ed.), Modifying lipids for use in food (pp.369-387). Cambridge: Woodhead Publishing Limited.

13. Powel, S.R. (2000). The antioxidant properties of zinc. Journal of Nutrition, 120 (5), 1447-1454.

14. Rankin, C.W., Nriagu, J. O., Aggarwal, J. K., Arowolo, T. A., Adebayo, K., Flegal, A. R. (2005). Lead contamination in cocoa and cocoa products: Isotopic evidence of global contamination. Environmental Health Perspectives, 113 (10), 1344 1348. DOI: 10.1289/ehp.8009.

15. Schinella, G., Mosca, S., Cienfuegos-Jovellanos, E., Pasamar, M.A., Muguerza, B., \& Ramon, D. (2010). Antioxidant properties of polyphenol-rich cocoa products industrially processed. Food Research International, 43(6), 1614-1623. DOI:10.1016/j. foodres.2010.04.032.

16. Thomas, E. Y. (2015). Assessment of Heavy Metal Concentration and Fractionation in Selected Dumpsite Soils within Ibadan Metropolis Nigeria. Journal of Agriculture and Ecology Research International, 4 (3), 117-127. DOI: 10.9734/JAERI/2015/17855.

17. Vitola, V., \& Strautnieks A. (2004). Biological activity of confectionery industry by- product cocoa shell. Innovation development trends of food products: International scientific - practical conference, 12 May 2004 (pp.129-135). Jelgava, Latvia: Latvia University of Agriculture.

18. Vitola, V., Karklina, D., \& Strautnieks, A. (2005). Antioxidant activity of extracts from processed cocoa bean products. Accessing useful Technologies optimizing food safety and nutrition: $4^{\text {th }} \mathrm{In}$ ternational Congress on Food Technology, 18-19 February 2005 (pp.274-278). Athens, Greece: Hellenic Association of Food Technologists \& Department of Food Technology, Technological Educational Institution of Athens. 